\title{
Prospective 6 Weeks Follow-up Post-cholecystectomy: The Predictive Value of Pre-Operative Symptoms
}

\author{
M. C. Mertens • J. De Vries • V. P. W. Scholtes • \\ P. Jansen - J. A. Roukema
}

Received: 3 July 2008 / Accepted: 24 September 2008 /Published online: 16 October 2008

(C) 2008 The Author(s). This article is published with open access at Springerlink.com

\begin{abstract}
Objective Many patients with symptomatic cholelithiasis report persisting symptoms after elective cholecystectomy. The current prospective follow-up study aims at the identification and valuation of risk factors for negative symptomatic outcome at 6 weeks.

Methods Consecutive patients $(n=183)$, age 18-65 years, indicated for elective cholecystectomy due to symptomatic cholelithiasis, completed a self-report questionnaire. At 6 weeks post-operatively, the same self-report questionnaires were completed $(n=129)$. Predictors of the persistence and emergence of biliary and dyspeptic symptoms at 6 weeks postcholecystectomy were investigated using univariate and multivariate logistic regression.

Results At 6 weeks post-operatively, the report of post-operative biliary symptoms was independently predicted by preoperative dyspeptic symptoms $(\mathrm{OR}=6.60)$ and bad taste $(\mathrm{OR}=3.55)$. Pre-operative flatulence was an independent predictor of the report of biliary and dyspeptic symptoms $((\mathrm{OR}=3.33)$ and $(\mathrm{OR}=3.27)$, respectively $)$ and persisting biliary symptoms $(\mathrm{OR}=4.21)$. Predictors of symptomatic outcome were only identified in women, not in men.

Conclusion Patients with pre-operative dyspeptic symptoms, notably bad taste and flatulence, have an increased risk of negative post-cholecystectomy outcomes at 6 weeks. A symptom-specific approach should lead to optimalization of the indication of cholecystectomy and information of patients. Known risk factors for long-term outcomes might be valuable in female patients only.
\end{abstract}

Keywords Cholecystectomy $\cdot$ Prediction $\cdot$ Symptoms

M. C. Mertens $\cdot$ J. De Vries $(\bowtie) \cdot J$. A. Roukema

CoRPS - Center of Research on Psychology in Somatic diseases,

Department of Medical Psychology, Tilburg University,

P.O. Box 90153, 5000 LE Tilburg, The Netherlands

e-mail: j.devries@uvt.nl

e-mail: JVries@elisabeth.nl

P. Jansen · J. A. Roukema

Department of Surgery, St. Elisabeth Hospital,

P.O. Box 90151, 5000 LC Tilburg, The Netherlands

J. De Vries

Department of Medical Psychology, St. Elisabeth Hospital,

P.O. Box 90151, 5000 LC Tilburg, The Netherlands

V. P. W. Scholtes

Department of Surgery, Diakonessenhuis Utrecht,

P.O. Box 80250, 3508 TG Utrecht, The Netherlands

\section{Introduction}

Gallstone disease (cholelithiasis) is a common condition in the Western world. In the Netherlands, 32,000 patients are yearly diagnosed with this condition. ${ }^{1}$ The majority of patients remains asymptomatic and only $20 \%$ of patients develop clinical symptoms. ${ }^{2-4}$ Symptomatic gallstone disease is typically diagnosed after an episode of biliary pain, which is defined as a severe steady pain, lasting more than 15$30 \mathrm{~min}$, usually located in the epigastrum and/or right upper quadrant, sometimes radiating to the back, ${ }^{2,5}$ which is often accompanied by dyspeptic symptoms. ${ }^{6-9}$ However, some patients experience mild dyspeptic symptoms without biliary colics. ${ }^{10}$ Additional ultrasonography is recommended, ${ }^{2,9,11}$ as clinical symptoms are not consistently related to the presence of gallstones. ${ }^{11-14}$ Professional guidelines propose conservative treatment (wait and see) in asymptomatic cholelithiasis $^{2,9,15}$ and cholecystectomy in symptomatic 
cholelithiasis. In biliary pain without stones, cholecystectomy is occasionally indicated ${ }^{10}$ following additional surgical consultation. $^{2}$

Elective cholecystectomy is widely performed in $70 \%$ of the symptomatic patients. ${ }^{16}$ In the Netherlands, cholecystectomy is performed in 19,000 patients a year. ${ }^{1}$ The majority of patients report positive outcomes and relief rates for biliary pain (86-96\%), upper abdominal pain (66$77 \%$ ), and dyspepsia $(46-89 \%)^{13}$ are high. However, a substantial group of patients report persistence of preexistent biliary $(5.5-19.5 \%)$ and dyspeptic symptoms $(27.3-43.2 \%){ }^{8,17,18}$ Thus, recognition of patients with a high risk of negative outcomes is crucial.

In literature, pre-operative dyspeptic symptoms, the use of psychotropic medication, and a long history of pain, symptoms, and biliary attacks are mentioned as potential predictors of poor outcome and persisting pain ${ }^{17-19}$ at 6 months post-cholecystectomy. Although clinical experience indicates that most patients experience a major reduction of symptoms at 6 weeks post-cholecystectomy, ${ }^{20}$ no studies have explored predictors of symptomatic outcome at this time point. The present prospective follow-up study aims at the identification and the valuation of predictors of negative symptomatic outcomes at 6 weeks after cholecystectomy.

\section{Methods}

\section{Patients}

Between March 2006 and August 2007, all patients between 18 and 65 years with diagnosed cholelithiasis (diagnosis K80 from International Statistical Classification of Diseases and Related Health Problems (ICD-10)), awaiting an elective laparoscopic cholecystectomy at the department of Surgery of the St. Elisabeth Hospital in Tilburg, the Netherlands, were eligible for the study. Exclusion criteria were: patients with ASA III or IV, undergoing an emergency procedure or intended open cholecystectomy, insufficient knowledge of the Dutch language, choledocholithiasis, cholangitis, known pregnancy, known liver cirrhosis, history of abdominal malignancy, previous upper abdominal surgery (precluding laparoscopic approach), and psychiatric diseases.

\section{Procedure}

During patients' visit to the outpatient clinic, the surgeon performed a physical examination and explained the surgical and anesthetic procedures. Patients were informed about the general prognosis after cholecystectomy and the risk of complications. Furthermore, the surgeon introduced the study and asked the patients to participate. Nurses informed patients further about the operation and the study, and handed out written information and the first set of questionnaires. Patients read the information at home and signed informed consent before participation. Pre-operatively, records were checked for medical history, comorbidity, and medication use. Before admission for cholecystectomy, patients completed the first questionnaires, which could be returned by mail or delivered to the nurses at the ward. In case the questionnaires were not returned 5 to 3 days before surgery, patients received a telephone call to remind them to complete the questionnaire. Patients who returned their first set of questionnaires after surgery were excluded from the study.

Six weeks after surgery, patients were sent another selfreport questionnaire. Eight weeks and 10 weeks after surgery, a phone call reminded the patients to return the post-operative questionnaire to the hospital, if necessary. The protocol of the study was approved by the local ethics committee.

\section{Questionnaires and Medical Files}

Questionnaires comprised self-reported demographic and clinical information. The demographic questionnaire asked about sex, age, marital status, educational level, and work. Furthermore, patients completed a self-constructed symptom checklist, which asked about the presence of symptoms in the past week. Symptoms were collected from biliary patients participating in focus groups. Following a study of Weinert et al., ${ }^{17}$ symptoms were categorized into symptom complexes, namely biliary symptoms (upper abdominal pain, nausea, vomiting), dyspeptic symptoms (bad taste, heartburn, under abdominal pain, diarrhea, and flatulence), and non-specific symptoms (general malaise, fatigue, weight change, decrease in sexual functioning, and other health complaints not mentioned in the checklist). Medical files were checked for the experience of biliary and dyspeptic symptoms ever before visiting the outpatient clinic. After surgery, surgical reports were checked for the presence of gallstones/sludge and conversion to open surgery.

\section{Surgical and Anesthetic Procedure}

Open introduction was performed in all patients regardless of previous abdominal surgery. Pneumoperitoneum was created using the subumbilical trocar with an intraabdominal pressure up to $12 \mathrm{mmHg}$. Three trocars for instruments were inserted. The dissection of the cystic artery and cystic duct, identifying Calot's triangle, was performed using a three-point 'flag' technique. The cystic duct and artery were clipped and transsected. After 
complete dissection of the gallbladder, it was removed either through the subumbilical or subxyphoidal trocar. Fascia defects as a result of the insertion of the $10 \mathrm{~mm}$ trocar and the open introduction of the subumbilical trocar were closed. No suction drains were left in the subhepatic space at the end of the procedure.

In principle, all patients were subjected to a standard anesthetic regime. As premedication, patients received paracetamol $1,000 \mathrm{mg}$ supp. and atropine $0.5 \mathrm{mg}$ i.m. Patients $<60$ years and $>60 \mathrm{~kg}$ received diazepam $10 \mathrm{mg}$. p.o.; patients $>60$ years and $<60 \mathrm{~kg}$ received diazepam $5 \mathrm{mg}$. p.o. Perioperative anesthesia consists of propofol $1.5-2.5 \mathrm{mg} / \mathrm{kg}$, sufenta $0.25 \mu \mathrm{g} / \mathrm{kg}$, and rocuronium $0.6 \mathrm{mg} / \mathrm{kg}$. Standard post-operative analgetics were paracetamol $4 \mathrm{dd} 1,000 \mathrm{mg}$ supp. and morphine $6 \mathrm{dd} 10 \mathrm{mg}$ s during the first $48 \mathrm{~h}$ post-operatively, until patients' indicated pain was acceptable. If necessary, patients received additional diclofenac 2 dd 100 mg supp.

\section{Statistical Analyses}

Pre-operative differences between responders (patients who returned their questionnaires at 6 weeks) vs. non-responders and dropouts (patients who ended participation within 6 weeks) were investigated by chi-square tests (using Fisher's exact test when appropriate) and Student's $t$ tests. Changes in symptoms were examined by the McNemar test. Analyses were performed both for specific symptoms and symptom complexes.

Furthermore, persistence and emergence rates were calculated. Therefore, the population under study was divided in two subgroups categorized by the presence (group 1) or absence (group 2) of self-reported preoperative biliary or dyspeptic symptoms. Patients with pre-operative biliary symptoms (group 1) reported biliary symptoms only or both biliary and dyspeptic symptoms. Patients without pre-operative biliary symptoms (group 2) suffered from dyspeptic symptoms only. Likewise, patients with and without pre-operative dyspeptic symptoms were categorized into two groups. Persistence was defined as reporting the symptoms both before and after cholecystectomy. Emergence was defined as not reporting the symptoms pre-operatively, but reporting the symptoms at 6 weeks post-cholecystectomy.

To discern which pre-operative symptoms predicted the post-operative report, the persistence, and the emergence of post-operative symptoms, we used univariate logistic regression. Furthermore, significant univariate predictors of each outcome were entered in a multivariate regression model (method enter) to assess the relative strength of each predictor. In both outcome and predictors, we differentiated between symptom complexes and specific symptoms.
A $p$ value $<.050$ indicated statistical significance. Statistical analyses were performed using SPSS version 14.0.1.

\section{Results}

\section{Patient Characteristics}

Figure 1 provides an overview of the population across time. Of all 241 patients visiting the outpatient clinic and being approached for participation, 211 received the first questionnaire. Statistical analyses were performed on 183 patients (response rate $86.7 \%$ ). Within 6 weeks, five patients ended participation. Six weeks after cholecystectomy, data were available from 129 patients (response rate $70.5 \%$ ). Because of missing values, final statistical analyses were performed on 126 patients. In $94.0 \%$ of the patients, biliary stones or sludge were demonstrated by ultrasonic tomography. Pre-operatively, endoscopic sphincterotomy had been performed in eight patients. Laparoscopic cholecystectomy was converted to an open procedure in six patients. Table 1 shows the demographic and clinical characteristics of the patient group. Pre-operatively, participants in the study did not differ from non-responders and patients who ended participation within 6 weeks. Among the participants, $74.3 \%$ were females and the mean age was $46.0 \pm 11.4$ years. Female patients were younger than male

Pre-operatively

Total number of patients approached

Expectative management

Refused participation

Received the pre-operative questionnaires

Not returned pre-operative questionnaires

Population pre-operatively

Ended participation within six weeks post-operatively

Six weeks post-cholecystectomy

Received questionnaires at six weeks

Not returned questionnaires at six weeks

Population post-operatively

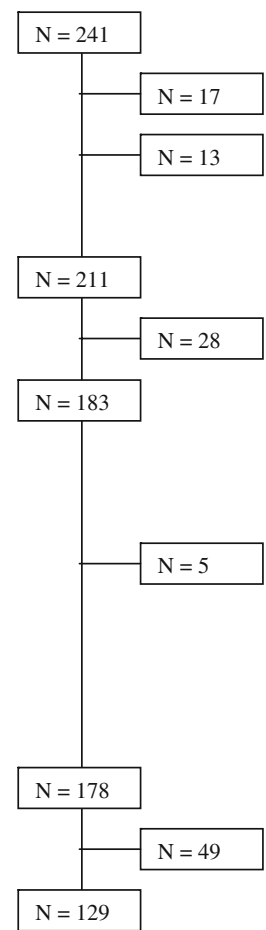

Figure 1 Flow chart of the population in the course of 6 weeks. 
Table 1 Baseline Characteristics

\begin{tabular}{|c|c|}
\hline & $\begin{array}{l}\text { Population } \\
n=183\end{array}$ \\
\hline \multicolumn{2}{|l|}{ Demographic characteristics } \\
\hline Female patients $(\%)$ & 74.3 \\
\hline Age $(M \pm \mathrm{SD})$ & $46.0 \pm 11.4$ \\
\hline \multicolumn{2}{|l|}{ Highest level of education } \\
\hline Primary and/or lower vocational education (\%) & 20.6 \\
\hline Secondary education $(\%)$ & 45.6 \\
\hline Higher education $(\%)$ & 6.1 \\
\hline Higher professional education or university (\%) & 27.8 \\
\hline Working under payment (\%) & 72.4 \\
\hline \multicolumn{2}{|l|}{ Marital status } \\
\hline Single $(\%)$ & 6.1 \\
\hline Widowed or divorced $(\%)$ & 6.6 \\
\hline Married or cohabitant $(\%)$ & 87.3 \\
\hline \multicolumn{2}{|l|}{ Comorbidities } \\
\hline Coronary arterial diseases $(\%)$ & 20.3 \\
\hline Pneumonal diseases $(\%)$ & 7.4 \\
\hline Abdominal diseases $(\%)$ & 25.0 \\
\hline Kidney diseases $(\%)$ & 2.0 \\
\hline Urogenital diseases $(\%)$ & 9.5 \\
\hline Neurological diseases (\%) & 11.5 \\
\hline Rest category of comorbidities (\%) & 48.0 \\
\hline \multicolumn{2}{|l|}{ Self-reported medication use } \\
\hline Analgesics (\%) & 37.8 \\
\hline Psychotropic medication (\%) & 10.1 \\
\hline Other medication $(\%)$ & 46.7 \\
\hline \multicolumn{2}{|l|}{ Pre-operative symptoms (self-reported) } \\
\hline Cholelithiasis-specific (\%) & 73.6 \\
\hline Dyspeptic (\%) & 66.7 \\
\hline Free of symptoms (\%) & 14.3 \\
\hline Frequency of biliary colics $(M \pm \mathrm{SD})$ & $5.47 \pm 7.68$ \\
\hline Demonstrated gallstones (\%) & 94.0 \\
\hline Pre-operative symptoms $\leq 6$ months (\%) & 68.3 \\
\hline Pre-operative symptoms $\geq 7$ months (\%) & 31.3 \\
\hline
\end{tabular}

patients $(50.7 \pm 9.6$ years vs. $44.5 \pm 11.6$ years; $(t=3.30$ $p=.001))$. Male patients more often reported urogenital diseases $(p=.034)$ than female patients.

\section{Pre-operative Symptoms}

In the week before visiting the outpatient clinic, $73.6 \%$ of the patients experienced biliary symptoms and $66.7 \%$ of the patients experienced dyspeptic symptoms (Table 1). Furthermore, $14.3 \%$ of all patients $(n=27)$ did not report any biliary or dyspeptic symptoms. In the week before surgical consultation, female patients reported more pre-operative biliary symptoms than male patients (78.5\% vs. 59.6\%, $p=.019$ ), whereas male patients more often reported to be free of symptoms than female patients $(25.5 \%$ vs. $10.4 \%$, $p=.021)$. Moreover, examination of medical files revealed that $84.7 \%$ and $73.2 \%$ of the patients had ever experienced biliary and dyspeptic symptoms. More specifically, 26.8\% had experienced only biliary symptoms, $15.3 \%$ had experienced only dyspeptic symptoms, whereas $57.9 \%$ of the patients had ever experienced both biliary and dyspeptic symptoms. Patients reported a mean of $5.5 \pm 7.7$ biliary attacks. Pre-operatively, upper abdominal pain was most frequently reported $(66.5 \%)$, followed by nausea $(39.3 \%)$ and flatulence (36.1\%). Moreover, $55.2 \%$ of all patients reported non-specific symptoms. Female patients more often reported bad taste $\left(\chi^{2}=5.27, p=.022\right)$, upper abdominal pain $\left(\chi^{2}=4.25, p=.039\right)$, nausea $\left(\chi^{2}=9.70 ; p=.002\right)$, diarrhea $\left(\chi^{2}=4.80, p=.029\right)$, and non-specific symptoms $\left(\chi^{2}=6.41, p=.011\right)$ than male patients.

\section{Course of Symptoms}

In the time between the pre-operative measurement and 6 weeks after cholecystectomy, five patients received an endoscopic sphincterotomy, of which two patients already received this procedure pre-operatively. Furthermore, a general improvement was observed. The number of patients reporting biliary and dyspeptic symptoms reduced to $25.4 \%$ and $50.8 \%$, respectively $\left(\chi^{2}=47.38, p<.001\right.$ and $\chi^{2}=5.56$, $p=.018)$. More specifically, the number of patients reporting bad taste, heartburn, upper abdominal pain, nausea, vomiting, and under abdominal pain reduced significantly over 6 weeks' time (see Table 2). The percentage of patients reporting to be free of symptoms increased to $44.4 \%\left(\chi^{2}=47.38, p<.001\right)$ (see Fig. 2).

In spite of the general improvements over 6 weeks' time, biliary symptoms persisted in $27.8 \%$ of the patients with pre-operative biliary symptoms, whereas biliary symptoms emerged in $17.1 \%$ of the patients with only pre-operative dyspeptic symptoms. Persistence of dyspeptic symptoms was reported in $57.3 \%$ of the patients biliary, dyspeptic, and

Table 2 Self-reported Symptoms Pre-operatively and 6 Weeks after Cholecystectomy (Total Population)

\begin{tabular}{lccc}
\hline & $\begin{array}{c}\text { Baseline } \\
(n=183)\end{array}$ & $\begin{array}{l}\text { Follow-up } \\
\text { 6 weeks }(n=126)\end{array}$ & $p$ \\
\hline Symptoms & & & \\
Bad taste (\%) & 24.0 & 12.7 & $.001^{*}$ \\
Heartburn (\%) & 25.1 & 15.1 & $.015^{*}$ \\
Upper abdominal pain (\%) & 66.5 & 19.8 & $<.001^{*}$ \\
Nausea (\%) & 39.3 & 13.5 & $<.001^{*}$ \\
Vomiting (\%) & 14.8 & 3.2 & $.001^{*}$ \\
Under abdominal pain (\%) & 24.6 & 8.7 & $.003^{*}$ \\
Diarrhea (\%) & 18.0 & 13.5 & .839 \\
Flatulence (\%) & 36.1 & 26.2 & .082 \\
Other health & 55.2 & 46.8 & .268 \\
$\quad$ complaints (\%) & & & \\
\end{tabular}

McNemar tests were used to analyze changes in symptoms over time * Significance $p<.050$ 
Pre- and postoperative symptoms in the total population

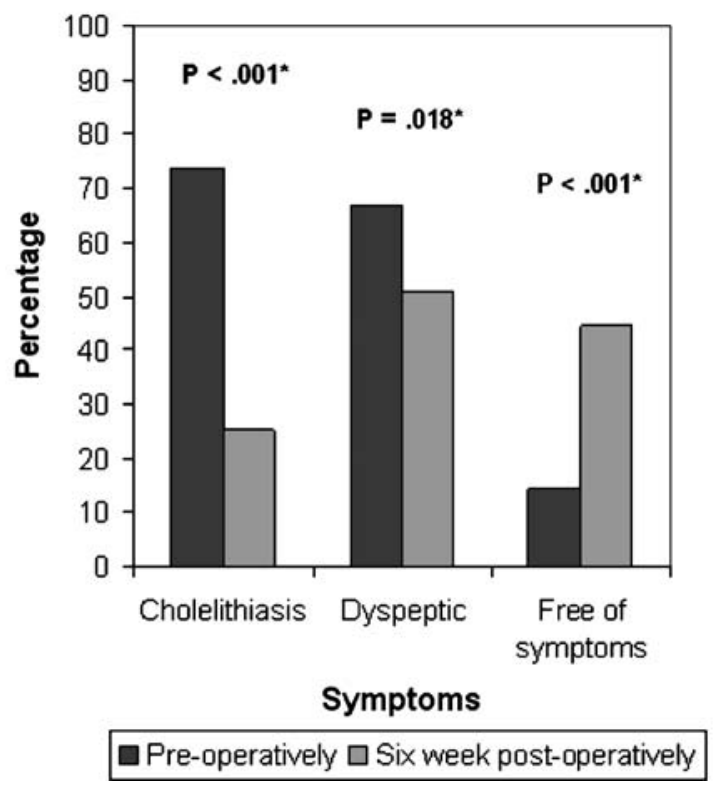

Figure 2 Report of symptoms in the total population.

non-specific symptoms. At 6 weeks, dyspeptic symptoms emerged in $38.6 \%$ of the patients who reported preoperative biliary symptoms only.

Symptom- and Sex-specific Patterns of the Course of Symptoms

At 6 weeks post-cholecystectomy, patients with and without demonstrated biliary stones and/or sludge reported postoperative biliary and dyspeptic symptoms to the same extent. Subgroups of patients with and without preoperative biliary symptoms experienced post-operative dyspeptic symptoms to the same extent $(45.7 \%$ and $52.2 \%$, respectively). Furthermore, patients with pre-operative dyspeptic symptoms reported post-operative biliary symptoms more often than patients without pre-operative dyspeptic symptoms ( $35.4 \%$ vs. $6.8 \% ; \chi^{2}=10.86, p=.001$ ).

Stratifying the self-reported improvements at 6 weeks post-cholecystectomy by sex, a different pattern of change was observed for male and female patients (see Fig. 3). Furthermore, no sex-bound patterns were found with regard to the emergence and persistence of biliary and dyspeptic symptoms after cholecystectomy.

Pre-operative Symptoms in the Prediction of Symptomatic Outcome

Univariate logistic regression analyses were used to identify the predictors of post-operative biliary and dyspeptic symptoms, and the persistence and emergence of biliary and dyspeptic symptoms (see Table 3). Duration of pre- operative symptoms and pre-operative medication use were not significant predictors. No univariate predictors could be distinguished for the emergence of dyspeptic symptoms at 6 weeks.

The differential value of the identified predictors was further explored in multivariate logistic regression analyses, inserting the univariate predictors for each outcome as variables (method enter). The report of biliary symptoms at 6 weeks post-operatively was independently predicted by pre-operative dyspeptic symptoms, bad taste, and flatulence (see Table 4). Both the report of post-operative dyspeptic symptoms and the persistence of biliary symptoms were independently predicted by pre-operative flatulence. Other univariate predictors of post-operative symptomatic outcomes were non-significant.

Eligibility of Pre-operative Symptoms in the Prediction Symptomatic Outcome

First of all, sex-specific predictors were investigated by univariate logistic regression analysis (Table 5). Predictors of the post-operative report and the persistence of biliary and dyspeptic symptoms were identified in female patients only, and not in male patients. In both men and women, no predictors were distinguished for the development of biliary and dyspeptic symptoms. Moreover, the univariate predictors of each outcome were simultaneously entered in multivariate logistic regression analyses. These analyses could only be performed on the population of female patients. In female patients, the post-operative experience of biliary symptoms was independently predicted by bad taste only (OR=3.73, $p=.008 ; 95 \%$ CI $1.42-9.84)$. At 6 weeks, the report of dyspeptic symptoms was predicted

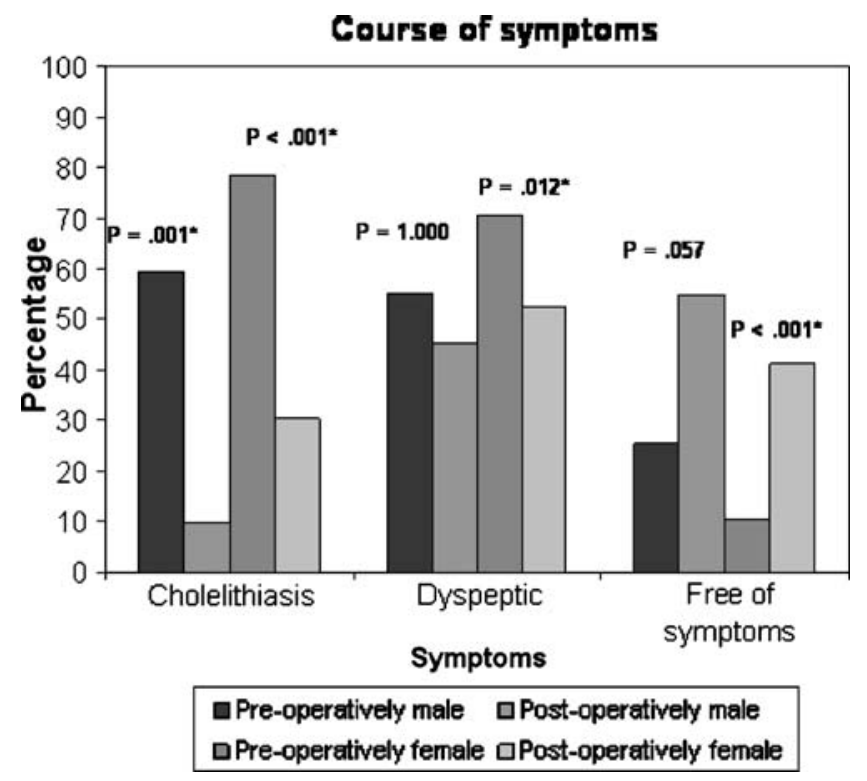

Figure 3 Course of symptoms over 6 weeks' time. 
Table 3 Univariate Predictors of Post-operative Symptoms at 6 Weeks (Total Population)

\begin{tabular}{|c|c|c|c|c|}
\hline Post-operative outcome & Pre-operative predictor & OR & $95 \% \mathrm{CI}$ & $p$ \\
\hline \multirow[t]{6}{*}{ Report of biliary symptoms } & Dyspeptic symptoms & 7.48 & $2.13-26.27$ & $.002 *$ \\
\hline & Sex & 4.10 & $1.15-14.58$ & $.029^{*}$ \\
\hline & Bad taste & 4.00 & $1.67-9.55$ & $.002 *$ \\
\hline & Heartburn & 2.38 & $1.01-5.60$ & $.047 *$ \\
\hline & Nausea & 2.38 & $1.05-5.38$ & $.038^{*}$ \\
\hline & Flatulence & 3.36 & $1.46-7.73$ & $.004 *$ \\
\hline \multirow[t]{3}{*}{ Report of dyspeptic symptoms } & Dyspeptic symptoms & 2.13 & $1.01-4.51$ & $.047^{*}$ \\
\hline & Heartburn & 2.60 & $1.14-5.95$ & $.024^{*}$ \\
\hline & Flatulence & 3.54 & $1.62-7.75$ & $.002 *$ \\
\hline \multirow[t]{3}{*}{ Persistent biliary symptoms } & Dyspeptic symptoms & 6.73 & $1.46-31.09$ & $.015^{*}$ \\
\hline & Bad taste & 3.69 & $1.37-9.96$ & $.010^{*}$ \\
\hline & Flatulence & 2.83 & $1.09-7.35$ & $.033^{*}$ \\
\hline Emergent biliary symptoms & Flatulence & 13.13 & $1.32-130.24$ & $.028^{*}$ \\
\hline Persistent dyspeptic symptoms & Flatulence & 3.28 & $1.32-8.17$ & $.011 *$ \\
\hline
\end{tabular}

Univariate logistic regression analysis was used to investigate the prediction of post-operative outcomes at 6 weeks post-cholecystectomy * Significance $p<.050$

by heartburn and flatulence $(\mathrm{OR}=2.70, p=.040 ; 95 \% \mathrm{CI}$ $1.04-6.96$ and $\mathrm{OR}=2.91, p=.020 ; 95 \%$ CI $1.19-7.13$, respectively). For the prediction of persisting biliary symptoms, no independent predictors could be identified.

\section{Discussion}

Most people with gallbladder stones never become patients, as they remain asymptomatic. Elective cholecystectomy is performed in $70 \%$ of patients with symptomatic cholelithiasis $^{16}$ aiming at a release from pain and symptoms and preventing complications. Post-operatively, a significant group of patients report persisting symptoms. ${ }^{17-19,21-23}$ Furthermore, cholecystectomy entails the risk of common bile duct injury and mortality in $0.5 \%$ and $0.2 \%$ of the patients, respectively. ${ }^{24}$ Therefore, performance of elective cholecystectomy should be considered critically and recognition of patients with a high risk of negative outcomes is crucial. In this prospective follow-up study, we investigated the role of pre-operative symptoms in the prediction of negative symptomatic outcome. The results of this study show that pre-operative dyspeptic symptoms, or more specifically bad taste and flatulence, are independent predictors for the experience of biliary and dyspeptic symptoms and the persistence of biliary symptoms. Although sex does not predict post-operative outcome, predictors are only identified in female patients.

In the current study, all abdominal symptoms decrease after cholecystectomy (with the exception of diarrhea), which is also reported in studies with follow-up at 6 months $s^{17,25}$ or more than 1 year. ${ }^{23,26}$ In line with other studies, ${ }^{13,17}$ greatest improvement was found for biliary symptoms, whereas dyspeptic symptoms more often persisted and emerged. At 6 months after cholecystectomy or later, biliary symptoms are found to be persistent in 5.6$20.0 \%$ of the patients ${ }^{17}$ and dyspeptic symptoms are persistent in $10.0-40.2 \%$ of the patients. ${ }^{17,23,27}$ In the current study, we found higher percentages of $27.8 \%$ and $57.3 \%$ for persistent biliary and dyspeptic symptoms, which may be attributed to the timeframe of 6 weeks before follow-up. Approximately one third of the patients with biliary or dyspeptic symptoms only developed another type of symptoms at 6 weeks post-operatively. Although one

Table 4 Differential Value of Predictors of Post-operative Symptomatic Outcome (Total Population)

\begin{tabular}{|c|c|c|c|c|}
\hline Post-operative outcome & Pre-operative predictor & OR & $95 \% \mathrm{CI}$ & $p$ \\
\hline \multirow[t]{3}{*}{ Report of biliary symptoms } & Dyspeptic symptoms & 6.60 & $1.86-23.45$ & $.005^{*}$ \\
\hline & Bad taste & 3.55 & $1.38-9.17$ & $.009^{*}$ \\
\hline & Flatulence & 3.33 & $1.48-7.26$ & $.004^{*}$ \\
\hline Report of dyspeptic symptoms & Flatulence & 3.27 & $1.48-7.26$ & $.004 *$ \\
\hline Persistent biliary symptoms & Flatulence & 4.21 & $1.46-12.19$ & $.008^{*}$ \\
\hline
\end{tabular}

Multivariate logistic regression analysis was used to investigate the prediction of post-operative outcomes at 6 weeks post-cholecystectomy *Significance $p<.050$ 
Table 5 Univariate Predictors of the Report of Post-operative Symptoms at 6 Weeks (Female Patients)

\begin{tabular}{|c|c|c|c|c|}
\hline Post-operative outcome & Pre-operative predictor & OR & $95 \% \mathrm{CI}$ & $p$ \\
\hline \multirow[t]{3}{*}{ Report of biliary symptoms } & Dyspeptic symptoms & 5.29 & $1.45-19.28$ & $.012 *$ \\
\hline & Bad taste & 3.81 & $1.48-9.82$ & $.006^{*}$ \\
\hline & Under abdominal pain & 2.75 & $1.04-7.30$ & $.042 *$ \\
\hline \multirow[t]{2}{*}{ Report of dyspeptic symptoms } & Heartburn & 2.90 & $1.15-7.28$ & $.024^{*}$ \\
\hline & Flatulence & 3.09 & $1.29-7.43$ & $.012 *$ \\
\hline \multirow[t]{2}{*}{ Persistent biliary symptoms } & Heartburn & 2.94 & $1.08-8.05$ & $.036^{*}$ \\
\hline & Flatulence & 2.94 & $1.08-8.05$ & $.036^{*}$ \\
\hline Persistent dyspeptic symptoms & Flatulence & 3.15 & $1.15-8.60$ & $.025 *$ \\
\hline
\end{tabular}

Univariate logistic regression analysis was used to investigate the prediction of post-operative outcomes at 6 weeks post-cholecystectomy *Significance $p<.050$

study $^{17}$ reports a one-directional shift from pre-operative biliary to post-operative dyspeptic symptoms, the findings from the current study suggest a bidirectional shift from pre-operative biliary symptoms to post-operative dyspeptic symptoms and vice versa.

As cholecystectomy is not beneficial to all patients, distinguishing patients with a heightened risk of persisting and emerging symptoms at 6 weeks is important. Literature mentions pre-operative dyspeptic symptoms, pre-operative flatulence, and experiencing over three symptoms of flatulent dyspepsia as predictors of negative post-cholecystectomy outcomes, such as post-cholecystectomy syndrome and persistence of a bothersome symptom. ${ }^{17,25,28}$ In addition, the current study asserts that pre-operative dyspeptic symptoms, bad taste, and flatulence are associated with a three to seven times greater risk of post-operative biliary and dyspeptic symptoms. Furthermore, pre-operative flatulence is associated with a four times greater risk of persisting biliary symptoms after cholecystectomy. Awareness of these risk factors might have strong implications for clinical practice. Surgeons should be alert on the recognition of these patients during anamnesis and patients should be informed about their symptom-specific risk of negative post-cholecystectomy outcome. Furthermore, the existing knowledge on risk factors for negative symptomatic outcome should be integrated in clinical decision making, with regard to guidelines for the indication of cholecystectomy and consideration of alternative treatment options.

Sex has an ambiguous position as a predictor of postcholecystectomy symptomatic outcome. Although male sex is found to be a predictor of a 'not very successful' outcome $^{17}$ in literature, the current study indicates that sex is no predictor of self-reported symptoms or the persistence or emergence of these symptoms. However, predictors are only identifiable in female patients and not in male patients. The latter point has implications for knowledge from the existing literature on predictors of post-cholecystectomy outcome. As the bulk of studies do not differentiate between male and female patients, we recommend a careful interpretation of results and the inclusion of the variable 'sex' in the design of future studies on cholecystectomy.

This study has several limitations. As this is a singleinstitution study, generalization of the results to other health care centers might be limited. We investigated the predictive value of pre-operative symptoms, taking biliary or dyspeptic symptoms as feature of a clinical representation of cholelithiasis. Coinciding with biliary stones, dyspeptic symptoms are easily interpreted as a clinical feature of cholelithiasis. However, dyspeptic symptoms are quite common in the general population and may still be an isolated condition, even in the context of biliary stones. Therefore, although our results imply a relation between dyspeptic symptoms and postoperative outcome at 6 weeks, results should be interpreted with care. Unfortunately, we did not specifically investigate the combination of both biliary and dyspeptic symptoms or the interaction between biliary and dyspeptic symptoms on the prediction of 6 weeks symptomatic outcome. We recommend that this issue will be addressed in future research. Furthermore, this study investigated pre-operative symptoms as predictors of negative symptomatic outcome at 6 weeks post-cholecystectomy. Future studies should investigate the relation between symptomatic outcome at 6 weeks and longterm outcomes, or the post-cholecystectomy syndrome. Despite the small sample of male patients $(n=46)$, we found a sex difference in terms of the impossibility to identify predictors of negative symptomatic outcome in male patients, in contrast to several predictors in female patients. Extensive exploration of predictors should be aimed at a bigger sample of male patients and studies on predictors of long-term post-cholecystectomy outcomes should integrate sex as a potential variable. Another shortcoming in this study is the fact that symptomatic outcome is a one-dimensional outcome, indicating the presence of symptoms only. Within this measure, differentiation should be sought by investigating severity and duration, implications for all day living, and psychosocial consequences.

In summary, at 6 weeks post-cholecystectomy, $27.8 \%$ and $57.3 \%$ of the patients reported the persistence of pre-operative 
biliary and dyspeptic symptoms, respectively. Furthermore, $17.1 \%$ and $38.6 \%$ of the patients with only dyspeptic or only biliary symptoms developed another type of symptoms after cholecystectomy. Sex is no predictor of post-operative outcome, whereas pre-operative symptomatology is. Patients reporting pre-operative dyspeptic symptoms, bad taste, or flatulence have a heightened risk of experiencing postoperative biliary symptoms. Besides, patients with pre-operative flatulence are at risk for the experience of post-operative dyspeptic symptoms and the persistence of pre-existing biliary symptoms. Management of cholelithiasis should be patient tailored, thereby considering the prognosis after cholecystectomy differentially, based on the clinical presentation of preoperative symptoms. So far, predictors of post-operative symptomatic outcome have only been identified in female patients and not in male patients.

Open Access This article is distributed under the terms of the Creative Commons Attribution Noncommercial License which permits any noncommercial use, distribution, and reproduction in any medium, provided the original author(s) and source are credited.

\section{References}

1. Prismant: Landelijke LRM-informatie, 2005. http://www.prismant. nl/informatie-expertise/Thema's/zienkenhuisstatistieken.

2. SSAT patient care guidelines. Treatment of gallstone and gallbladder disease. J Gastrointest Surg 2007;11:1222-1224. doi:10.1007/s11605-007-0202-3.

3. Jacoby I, Scott TE. NIH Consensus Conference on laparoscopic cholecystectomy: are reforms necessary. JAMA 1993;270:320 321. doi:10.1001/jama.270.3.320.

4. Halldestam I, Enell LE, Kullman E, Borch K. Development of symptoms and complications in individuals with asymptomatic gallstones. Br J Surg 2004;91:734-738. doi:10.1002/bjs.4547.

5. Schoenfield LJCN, Dowling RH et al. Asymptomatic gallstones. Definition and treatment. Rom88 working team report no 5. Gastroenterol Int 1988;1:17-28.

6. Diehl AK. Symptoms of gallstone disease. Baillieres Clin Gastroenterol 1992;6:635-657. doi:10.1016/0950-3528(92)90044-F.

7. Kellow JE. Organic causes of dyspepsia, and discriminating functional from organic dyspepsia. Baillieres Clin Gastroenterol 1998;12:477-487. doi:10.1016/S0950-3528(98)90019-7.

8. Abu Farsakh NA, Stietieh M, Abu Farsakh FA. The postcholecystectomy syndrome. A role for duodenogastric reflux. J Clin Gastroenterol 1996;22:197-201. doi:10.1097/00004836199604000-00009.

9. NVVH, ed. Evidence Based Richtlijn. Onderzoek en behandeling van galstenen. Utrecht: NVVH, 2007.

10. Treatment of gallstone and gallbladder disease. SSAT patient care guidelines. J Gastrointest Surg. 2004;8:363-4. doi:10.1016/j. gassur.2003.11.025.
11. Diehl AK, Sugarek NJ, Todd KH. Clinical evaluation for gallstone disease: usefulness of symptoms and signs in diagnosis. Am J Med 1990;89:29-33. doi:10.1016/0002-9343(90)90094-T.

12. Kraag N, Thijs C, Knipschild P. Dyspepsia-how noisy are gallstones? A meta-analysis of epidemiologic studies of biliary pain, dyspeptic symptoms, and food intolerance. Scand J Gastroenterol 1995;30:411-421. doi:10.3109/00365529509093300.

13. Berger MY, Olde Hartman TC, Bohnen AM. Abdominal symptoms: do they disappear after cholecystectomy. Surg Endosc 2003;17:1723-1728. doi:10.1007/s00464-002-9154-6.

14. Berger MY, Olde Hartman TC, van der Velden JJIM, Bohnen AM. Is biliary pain exclusively related to gallbladder stones? A controlled prospective study. Br J Gen Pract 2004;54:574-579.

15. Aerts R, Penninckx F. The burden of gallstone disease in Europe. Aliment Pharmacol Ther 2003;18(Suppl 3):49-53. doi:10.1046/ j.0953-0673.2003.01721.x.

16. Keulemans YC, Venneman NG, Gouma DJ, van Berge Henegouwen GP. New strategies for the treatment of gallstone disease. Scand J Gastroenterol Supp1 2002;236:87-90. doi:10.1080/ 003655202320621526 .

17. Weinert CRAD, Jacobs D, Kane R. Relationship between persistence of abdominal symptoms and successful outcome after cholecystectomy. Arch Intern Med 2000;160:989-995. doi:10.1001/archinte.160.7.989.

18. Luman W, Adams WH, Nixon SN, McIntyre IM, Hamer-Hodges $D$, Wilson $G$ et al. Incidence of persistent symptoms after laparoscopic cholecystectomy: a prospective study. Gut 1996;39:863-866. doi:10.1136/gut.39.6.863.

19. Borly L, Anderson IB, Bardram L, Christensen E, Sehested A, Kehlet $\mathrm{H}$ et al. Preoperative prediction model of outcome after cholecystectomy for symptomatic gallstones. Scand J Gastroenterol 1999;34:1144-1152. doi:10.1080/003655299750024968.

20. Donceel P, Du Bois M. Fitness for work after laparoscopic and open cholecystectomy. Acta Chir Belg 1997;97:168-172.

21. Bisgaard T, Rosenberg J, Kehlet H. From acute to chronic pain after laparoscopic cholecystectomy: a prospective follow-up analysis. Scand J Gastroenterol 2005;40:1358-1364. doi:10.1080/ 00365520510023675.

22. Lublin MCD, Hiatt JR, Phillips EH. Symptoms before and after laparoscopic cholecystectomy for gallstones. Am Surg 2004;70:863-866.

23. Ross E, Zambon DG. Postcholecystectomy symptoms. A prospective study of gall stone patients before and two years after surgery. Gut 1987;28:1500-1504. doi:10.1136/gut.28.11.1500.

24. Shea JA, Healey MJ, Berlin JA, Clarke JR, Malet PF, Staroscik $\mathrm{RN}$ et al. Mortality and complications associated with laparoscopic cholecystectomy. A meta-analysis. Ann Surg 1996;224:609620. doi:10.1097/00000658-199611000-00005.

25. McMahon AJ, Ross S, Baxter JN, Russell IT, Anderson JR, Morran CG et al. Symptomatic outcome 1 year after laparoscopic and minilaparotomy cholecystectomy: a randomized trial. Br J Surg 1995;82:1378-1382. doi:10.1002/bjs.18008 21028.

26. Finan KR, Leeth RR, Whitley BM, Klapow JC, Hawn MT. Improvement in gastrointestinal symptoms and quality of life after cholecystectomy. Am J Surg 2006;192:196-202. doi:10.1016/j. amjsurg.2006.01.020.

27. Russello D, Di Stefano A, Scala R, Favetta A, Emmi S, Guastella T, Latteri F. Does cholecystectomy always resolve biliary disease. Minerva Chir 1997;52:1435-1439.

28. Bateson MC. Fortnightly review: gallbladder disease. BMJ 1999;318:1745-1748. 